\title{
Newborn follow-up after discharge from a tertiary care hospital in the Western Cape region of South Africa: a prospective observational cohort study
}

Jean Paul Muambangu Milambo ${ }^{1}$, KaWing Cho ${ }^{2}$, Charles Okwundu ${ }^{3}$, Abiola Olowoyeye ${ }^{2}$, Leonidas Ndayisaba ${ }^{4}$, Sanjay Chand ${ }^{5}$ and Mark H. Corden ${ }^{5,6^{*}}$

\begin{abstract}
Background: Current practice in the Western Cape region of South Africa is to discharge newborns born in-hospital within $24 \mathrm{~h}$ following uncomplicated vaginal delivery and two days after caesarean section. Mothers are instructed to bring their newborn to a clinic after discharge for a health assessment. We sought to determine the rate of newborn follow-up visits and the potential barriers to timely follow-up.

Methods: Mother-newborn dyads at Tygerberg Hospital in Cape Town, South Africa were enrolled from November 2014 to April 2015. Demographic data were obtained via questionnaire and medical records. Mothers were contacted one week after discharge to determine if they had brought their newborns for a follow-up visit, and if not, the barriers to follow-up. Factors associated with follow-up were analyzed using logistic regression.

Results: Of 972 newborns, 794 (82\%) were seen at a clinic for a follow-up visit within one week of discharge. Mothers with a higher education level or whose newborns were less than 37 weeks were more likely to follow up. The follow-up rate did not differ based on hospital length of stay. Main reported barriers to follow-up included maternal illness, lack of money for transportation, and mother felt follow-up was unnecessary because newborn was healthy.
\end{abstract}

Conclusions: Nearly 4 in 5 newborns were seen at a clinic within one week after hospital discharge, in keeping with local practice guidelines. Further research on the outcomes of this population and those who fail to follow up is needed to determine the impact of postnatal healthcare policy.

Keywords: Follow-up study, Hospital nursery, Low-income population, Newborn, Patient discharge, Pediatrics, South Africa

\section{Background}

Early discharge of healthy newborns from the postnatal wards is common in many parts of the world [1,2]. Early discharge is defined as a discharge from the hospital within $24 \mathrm{~h}$ of a vaginal delivery or in two days after a caesarean section. The impact of shorter length of stay on maternalnewborn health is not clear. Some studies favor early discharge, others found no significant difference, and some

\footnotetext{
* Correspondence: mcorden@chla.usc.edu

${ }^{5}$ Division of Hospital Medicine, Department of Pediatrics, Children's Hospital Los Angeles, 4650 Sunset Blvd, MS 94, Los Angeles, CA 90027, USA

${ }^{6}$ Department of Pediatrics, Keck School of Medicine, University of Southern California, Los Angeles, CA, USA

Full list of author information is available at the end of the article
}

demonstrated an increased risk for newborn readmission [3-7]. Appropriate follow-up has been recommended to mitigate the morbidity and mortality that may be associated with early discharge [8-11].

The first newborn follow-up visit plays a vital role in bridging care following the immediate newborn period in the hospital. Aside from establishing a relationship with a medical home, the purpose of the follow-up visit is to evaluate for signs/symptoms of infection, jaundice, feeding difficulties, and other issues that may manifest after the first few days of life. Follow-up is generally recommended within two days after discharge for shorter lengths of stay (less than $48 \mathrm{~h}$ ) up to the first few days following discharge 
for more prolonged perinatal hospitalizations [8, 9, 12]. When adhered to, such discharge guidelines appear to decrease the likelihood of hospital readmission [13, 14] and may allow for the detection of cases of neonatal sepsis in a region where the incidence is close to $10 \%$ [15].

In South Africa, healthy newborns are typically discharged with their mothers within $24 \mathrm{~h}$ after an uncomplicated vaginal delivery and the second day following an uncomplicated caesarean section delivery. Upon discharge, mothers are advised to bring their newborns for a followup evaluation at their local clinic within one week [16]. The proportion of newborns who follow up at the recommended time after hospital discharge in this region of South Africa is not yet known. The purpose of this study was to determine the number of newborns who have a follow-up visit within seven days and factors associated with failure to follow up in that time frame.

\section{Methods}

\section{Study design and setting}

We conducted a prospective observational cohort study from November 2014 to April 2015 in the postnatal wards at Tygerberg Hospital in Cape Town, South Africa. Tygerberg Hospital is a tertiary hospital that serves the Western Cape region of South Africa, which is home to 5.8 million inhabitants, with $75 \%$ living in the metropolitan area of Cape Town. Tygerberg Hospital primarily serves patients of low socioeconomic status without medical insurance [17]. The hospital attends roughly 7500 deliveries per year, a high percentage of which are to mothers referred from regional midwife obstetric units or secondary healthcare facilities for maternal or pregnancy-related conditions that cannot be managed at these facilities [18]. Mothers were considered to have a high-risk pregnancy if they had one or more of the following conditions: anemia, gestational diabetes, HIV, hypertension, or preeclampsia. Other conditions that may have been referred due to referring health unit concerns were not captured with our questionnaire.

\section{Sample size/data collection strategy}

Convenience sampling was used to recruit mothernewborn dyads on day of discharge from the postnatal wards at Tygerberg Hospital. Newborns who were admitted to the neonatal intensive care unit (NICU), had a congenital malformation, were $<34$ weeks gestational age, or born weighing $<1800 \mathrm{~g}$ were excluded from the study population. Mothers who were non-English speaking, had no means of telephone contact, or had a discrepancy in their discharge dates compared to their newborns were also excluded.

\section{Variable measures}

Prior to discharge, demographic and medical information from the mother-newborn dyads were collected. A directed questionnaire was used to collect maternal demographic information while data on maternal factors, including mode of delivery, maternal medical conditions and/or obstetric complications (e.g. gestational hypertension, diabetes, preeclampsia/eclampsia, urgent caesarean section), neonatal factors (sex, gestational age, birthweight), and length of stay were obtained from review of the medical records. Mothers were contacted by phone between seven and ten days after hospital discharge and asked if a newborn follow-up visit had taken place. Follow-up was defined as a visit to any type of healthcare facility to verify the health of the newborn. Those who had yet to attend a clinic visit within seven days after hospital discharge were asked if barriers existed that prevented follow-up. Participants who could not be reached on the first attempt were contacted again on two other occasions before being considered lost to follow-up and excluded from the final analysis.

\section{Data analysis}

Basic descriptive statistics were used to examine the frequency distribution of all variables. Bivariate logistic regression was used to determine the relationship between the predictor variables and the outcome variable (follow-up visit within seven days after being discharged from the hospital). Multivariable logistic regression was used to examine unique effects from all statistically significant predictors $(P<0.05)$ and predictors approaching statistical significance $(P<0.10)$, which were entered into the model simultaneously. Other items were dropped as a group, and a likelihood ratio test comparing the full and reduced model was conducted to test the effect of removing this set of items. 2-sided $P$-values of less than 0.05 were considered as statistically significant. The data were analyzed by using SPSS Version 20 (IBM SPSS Statistics, IBM Corporation, Armonk, NY).

\section{Results}

A total of 1150 mother-newborn dyads were eligible and recruited during the study period. Among the 1150 participants, 972 were included in the final analysis after excluding 82 participants who could not be reached by phone and an additional 96 participants for whom there were incomplete data.

\section{Sample characteristics}

Table 1 summarizes the characteristics of the 972 mothernewborn dyads.

Of the mothers, $92 \%$ had at least some secondary school education, with $36 \%$ receiving their secondary school certificate or higher. A majority of mothers reported having no source of income (82\%) and almost all endorsed not having medical insurance (99\%). Only $21 \%$ of mothers had an existing pregnancy-related condition prior to delivery (gestational diabetes, hypertension, preeclampsia, anemia), while $19 \%$ had a delivery complication, the most common 
Table 1 Maternal and newborn characteristics

\begin{tabular}{|c|c|c|c|}
\hline Total & $\mathrm{n}=972(\%)$ & & \\
\hline \multicolumn{4}{|l|}{ Maternal characteristics } \\
\hline Education level & & Pregnancy Complication & \\
\hline Primary and under & $83(8)$ & None & $584(60)$ \\
\hline Secondary & $540(56)$ & Maternal condition ${ }^{\mathrm{b}}$ & $206(21)$ \\
\hline Matric ${ }^{a}$ or higher & $349(36)$ & Delivery condition ${ }^{c}$ & $182(19)$ \\
\hline Race & & Number of children & \\
\hline African & $576(59)$ & 0 & $284(29)$ \\
\hline Mixed & $379(39)$ & 1 & $291(30)$ \\
\hline White/Other & $17(2)$ & 2 & $242(25)$ \\
\hline Medical Insurance & & $3+$ & $155(16)$ \\
\hline No & $958(99)$ & Delivery type & \\
\hline Yes & $14(1)$ & Vaginal & $569(59)$ \\
\hline Travel time to local clinic & & Elective C-section & $247(25)$ \\
\hline$>1$ hour & $507(52)$ & Emergent C-section & $156(16)$ \\
\hline$<1$ hour & $455(47)$ & & \\
\hline Unknown & $10(1)$ & & \\
\hline \multicolumn{4}{|l|}{ Maternal Income } \\
\hline Salary/Wages/Grants & $160(16)$ & & \\
\hline No income & $799(82)$ & & \\
\hline Refuse to disclose & $13(1)$ & & \\
\hline \multicolumn{4}{|l|}{ Newborn characteristics } \\
\hline Birth weight (grams) & & Length of stay (hours) & \\
\hline$<2500$ & $247(25)$ & $0-24$ & $255(26)$ \\
\hline$\geq 2500$ & $725(75)$ & $25-48$ & $209(22)$ \\
\hline Gestational Age (weeks) & & $49-72$ & $218(22)$ \\
\hline $34-36$ & $197(20)$ & $73-96$ & $168(17)$ \\
\hline $37-39$ & $594(61)$ & $>96$ & $122(13)$ \\
\hline $40-42$ & $178(18)$ & Planned Diet & \\
\hline \multirow[t]{2}{*}{ Unknown } & $3(<1)$ & Breastmilk & $911(94)$ \\
\hline & & Formula & $61(6)$ \\
\hline \multicolumn{4}{|l|}{ Outcomes } \\
\hline \multicolumn{4}{|c|}{ Follow-up within 7 days of discharge } \\
\hline Yes & $794(82)$ & & \\
\hline No & $177(18)$ & & \\
\hline
\end{tabular}

${ }^{\mathrm{a}}$ Matric: completion or graduation from secondary school

${ }^{b}$ Maternal condition: anemia, gestational diabetes, HIV, hypertension, preeclampsia

'Delivery condition: breech presentation, failure to progress, fetal distress, placental abruption, twin gestation

being fetal distress and breech presentation. Among newborns, 569 (59\%) were born by vaginal delivery and 403 (41\%) were born by caesarean section, with almost $40 \%$ of these surgeries considered to be emergent cases. About one-fourth $(26 \%)$ of mothers with their newborns were discharged within $24 \mathrm{~h}$ after delivery, with almost half of the cohort (48\%) being discharged within $48 \mathrm{~h}$. The majority of mothers (69\%) who delivered via normal vaginal delivery were discharged between 6 and 48 h, with the average length of stay being $46.3 \mathrm{~h}$. Those mothers who delivered via caesarean section were typically discharged between 48 to $120 \mathrm{~h}$ (75\%), with a mean (standard deviation) length of stay of $78.6 \mathrm{~h}$ (17.4).

\section{Follow-up characteristics and predictors}

Eighty-two percent of newborns had an outpatient follow-up visit within seven days after discharge. Of these visits, $27 \%$ occurred within the first two days after hospital discharge 
and $62 \%$ occurred at 3-5 days after discharge. Demographic profiles of the mother-newborn dyads that followed up and those who did not were similar. Among those who had yet to have a follow-up visit, the primary reasons reported for not following up included maternal illness, the newborn was well and therefore did not need to be seen, and no money for transport to the local clinic (Table 2).

Newborns born less than 37 weeks were more likely to follow up after hospital discharge in bivariate and multivariable analysis (OR 1.67, 95\% CI [1.07, 2.63]). Mothers who completed secondary school or achieved a higher level of education were more likely to bring their newborn for a follow-up visit in the first week after discharge compared to mothers who had some secondary school education or less (OR 1.47, 95\% CI [1.02, 2.12]). There was no significant association between time of hospital discharge, including early discharges $<48 \mathrm{~h}$, and increased follow-up after hospital discharge. Number of previous children, type of delivery, pregnancy condition, newborn birth weight, travel time to the nearest clinic and maternal income were also not associated with differences in follow-up utilization (Table 3).

\section{Discussion}

Our study shows that 4 in 5 newborns have a follow-up visit within seven days after discharge from a large tertiary hospital. The follow-up rate seen in this South African cohort is on the high end compared to other studies looking at newborn follow-up. In countries like the United States, follow-up rates varied depending on area and postnatal services available. Madlon-Kay and Ashe found an $84 \%$ newborn follow-up rate within two weeks after birth from a community hospital, but this included home visits as well as clinic visits, and no patient was discharged prior to $24 \mathrm{~h}$ [19]. Other studies have shown follow-up rates at $37 \%$ and $54 \%$ in the first $6-7$ days after discharge $[20,21]$.

In many low- and middle-income countries (LMIC), the follow-up rate is generally much lower with rates of $8 \%$ over the first week of life to $23-65 \%$ over the first six weeks following birth in areas of Asia and Africa [22-25]. The prevalence of home births in many of these areas is high; thus, knowledge of and access to postnatal care may

Table 2 Reasons given for not attending a newborn follow-up visit (multiple answers possible)

\begin{tabular}{ll}
\hline Reasons & $n=212$ \\
\hline Maternal illness & 68 \\
Baby is healthy & 61 \\
No money for transport & 54 \\
Long queue at the clinic & 10 \\
No reason given & 10 \\
Not informed about follow-up & 9 \\
\hline
\end{tabular}

be different than in our study cohort, where all deliveries took place in a tertiary healthcare facility in an urban setting. The relatively high-risk maternal population and near-universal receipt of some level of antenatal care may have sensitized this group to the importance of seeking healthcare through the postnatal period. Indeed, receipt of antenatal care has been associated with increased postnatal care utilization [23, 24]. At the same time, multiple studies have found that mothers who deliver at a health facility may be less likely to attend postnatal care than those who delivered outside of a facility, as the assumption is the mother and newborn have already been evaluated by a healthcare provider $[23,25]$.

Variability in obtaining postnatal care exists despite recommendations by the World Health Organization, the American Academy of Pediatrics, and South Africa's Maternity Guidelines Committee that newborn care should be obtained within the first few days of life, particularly if there is early discharge from a healthcare setting or a home delivery $[8,9,15]$. However, no significant difference was seen in follow-up rates among newborns discharged before $48 \mathrm{~h}$ and newborns discharged later. Reassuringly, late preterm newborns in our study were more likely to attend a followup visit after discharge than those born at term. The increased likelihood for follow-up among late preterm newborns is encouraging as they are a higher-risk group for readmission to the hospital [5].

Many studies have shown factors that affect utilization and attendance at postnatal visits in areas with low followup include lower income, lower maternal education level, multiparity, and living in a rural area $[19,23,25,26]$. Among our study cohort, higher level of education did play a role in increased attendance with the first newborn visit after hospital discharge; however, no association was seen with parity, maternal income distribution was skewed preventing analysis, and living area was not assessed. Greater travel distances between the family and a health facility is associated with increased child mortality and decreased maternal utilization of services in LMIC [27]. More than half of our study population reported living more than $1 \mathrm{~h}$ from the nearest clinic, but travel time was not associated with decreased follow-up.

The major reasons for not seeking newborn follow-up care after discharge were that mothers thought it was unnecessary or had an issue with access, particularly the cost of getting to a local facility for care. These responses match barriers identified in many other LMIC where utilization of postnatal care services is low, namely, from lack of emphasis on the importance of the postnatal visit and concerns with access, including transportation costs and distance to the nearest healthcare facility [22, 28-31]. Interestingly enough, maternal health issues were the most common reason for failing to follow up at a health clinic, underscoring the importance of the first follow-up 
Table 3 Factors associated with newborn follow-up visit after hospital discharge within seven days

\begin{tabular}{|c|c|c|c|c|c|c|}
\hline \multirow[b]{2}{*}{ Variable } & \multicolumn{3}{|c|}{ Bivariate analysis } & \multicolumn{3}{|c|}{ Multivariable analysis } \\
\hline & Odds Ratio & $95 \% \mathrm{Cl}$ & $p$-value & Odds Ratio & $95 \% \mathrm{Cl}$ & $p$-value \\
\hline \multicolumn{7}{|l|}{ Maternal Characteristics } \\
\hline \multicolumn{7}{|l|}{ Age (years) } \\
\hline$<21$ & Reference & & & & & \\
\hline $21-30$ & 0.76 & {$[0.41,1.39]$} & .369 & & & \\
\hline$>30$ & 0.77 & {$[0.41,1.44]$} & .77 & & & \\
\hline \multicolumn{7}{|l|}{ Education } \\
\hline Primary & 0.90 & {$[0.51,1.59]$} & .722 & 0.89 & {$[0.50,1.57]$} & .682 \\
\hline Secondary & Reference & & & & & \\
\hline Matric $^{\mathrm{a}}$ and higher & 1.43 & {$[0.99,2.05]$} & .054 & 1.47 & {$[1.02,2.12]$} & .037 \\
\hline \multicolumn{7}{|l|}{ Maternal Income } \\
\hline None & Reference & & & & & \\
\hline Salary/Wages/Grants & 0.96 & {$[0.62,1.48]$} & .841 & - & - & - \\
\hline \multicolumn{7}{|l|}{ Travel time to local clinic } \\
\hline$<1 \mathrm{~h}$ & Reference & & & & & \\
\hline$\geq 1 \mathrm{~h}$ & 0.82 & {$[0.59,1.15]$} & .252 & - & - & - \\
\hline \multicolumn{7}{|l|}{ Number of children } \\
\hline 0 & Reference & & & & & \\
\hline 1 & 0.70 & {$[0.45,1.08]$} & .107 & - & - & - \\
\hline 2 & 1.07 & {$[0.66,1.75]$} & .779 & - & - & - \\
\hline$\geq 3$ & 0.97 & {$[0.53,1.79]$} & .933 & - & - & - \\
\hline \multicolumn{7}{|l|}{ Pregnancy Complication } \\
\hline None & Reference & & & & & \\
\hline Maternal $^{b}$ & 1.06 & {$[0.71,1.59]$} & .777 & - & - & - \\
\hline Delivery $^{c}$ & 1.38 & {$[0.87,2.18]$} & .170 & - & - & - \\
\hline \multicolumn{7}{|l|}{ Delivery Type } \\
\hline Vaginal & Reference & & & & & \\
\hline Scheduled $\mathrm{CS}^{\mathrm{d}}$ & 1.21 & {$[0.81,1.80]$} & .343 & - & - & - \\
\hline Emergency CS & 0.98 & {$[0.63,1.54]$} & .944 & - & - & - \\
\hline \multicolumn{7}{|l|}{ Newborn characteristics } \\
\hline \multicolumn{7}{|l|}{ Gestational age } \\
\hline 34-36 weeks & 1.61 & {$[1.03,2.53]$} & .037 & 1.67 & {$[1.07,2.63]$} & .026 \\
\hline 37-42 weeks & Reference & & & & & \\
\hline \multicolumn{7}{|l|}{ Birth weight (grams) } \\
\hline $1800-2499$ & 1.15 & {$[0.79,1.69]$} & .466 & - & - & - \\
\hline $2500-4000$ & Reference & & & & & \\
\hline$>4000$ & 1.45 & {$[0.64,3.30]$} & .374 & - & - & - \\
\hline Sex (male) & 1.02 & {$[0.73,1.41]$} & .903 & & & \\
\hline \multicolumn{7}{|l|}{ Length of stay (hours) } \\
\hline $0-24$ & 1.12 & {$[0.71,1.77]$} & .620 & - & - & - \\
\hline $25-48$ & 1.03 & {$[0.65,1.66]$} & .889 & - & - & - \\
\hline 49-72 & Reference & & & & & \\
\hline 73-96 & 1.42 & {$[0.84,2.42]$} & .195 & - & - & - \\
\hline$>96$ & 1.61 & {$[0.87,2.95]$} & .127 & - & - & - \\
\hline
\end{tabular}

Matric: completion or graduation from secondary school

bMaternal condition: anemia, gestational diabetes, HIV, hypertension, preeclampsia

'Delivery condition: breech presentation, failure to progress, fetal distress, placental abruption, twin gestation

${ }^{\mathrm{d}} \mathrm{CS}$ caesarean section 
visit, which in most LMIC is typically a joint visit when both the mother's and the newborn's health are assessed and treated accordingly. Otherwise, most mothers in our cohort seemed to be aware of the existence of postnatal care services, as only a fraction reported not knowing about having to follow-up, which other studies have shown can be a significant hindrance to appropriate utilization of care [30, 31].

Although there was a surprisingly high rate of follow-up in our study population, there is still room for improvement. Currently, there are a handful of studies evaluating the efficacy of various strategies to improve follow-up rates. One strategy is to provide care coordination in the form of discharge follow-up appointments. Multiple studies have found a benefit to having an appointment date and time set prior to discharge to increase compliance with the first newborn visit $[32,33]$. Primary care intake coordination to help with appointment and rescheduling no-shows after hospital discharge, as well as home nursing visits and phone call checkins, have been shown to lead to increased compliance with and earlier timing of first follow-up visits [34-36]. Another option that has been employed in increasing health maintenance compliance is text message reminders [37]; a similar strategy for newborn follow-up could be beneficial. If health policy for newborn follow-up is to remain the same, stakeholders in the Western Cape Region might consider additional region-specific, culturally-competent strategies to increase follow-up rates.

The main strength of this study is the large cohort that was recruited and contacted for follow-up questioning. Limitations to the study included self-report of newborn follow-up, which could have introduced an element of reporting and/or self-selection bias. The mothers approached during recruitment may have been inclined to change their follow-up behavior because, through enrollment, they were sensitized to the need for proper newborn care and the advantages of timely follow-up. Our follow-up rate of over $80 \%$, which is on the high side compared to other studies, lends support to the possibility of inadvertently influencing the study population. The study population was obtained through a convenience sample in a specific healthcare setting and may also be prone to selection bias; thus, it may not be possible to generalize our results to the rest of the South African population. The cohort had a different demographic distribution than the general population given Tygerberg Hospital's catchment population and tertiary care status. Additionally, we chose to collect maternal income figures and analyze their association with newborn follow-up; it is possible that determining the household income of our study participants might have produced different results. Finally, our exclusion criteria (non-English-speaking, no cell phone contact) may have selected for a higher-educated, higher-income study population that would be more likely to follow up.

\section{Conclusions}

Follow-up among newborns after hospital discharge from a referral center in the Western Cape region of South Africa was found to be comparatively high at $82 \%$. No difference in follow-up rate was seen among those discharged at less than $48 \mathrm{~h}$ compared to those with longer lengths of stay. This finding suggests a continued need to further educate this potentially high-risk group on the importance of timely follow-up. Further research is needed to determine if lack of timely follow-up is associated with increased morbidity and mortality and to identify novel strategies to overcome barriers preventing appropriate newborn follow-up after hospital discharge.

\section{Abbreviations \\ LMIC: low- and middle-income countries}

\section{Acknowledgements}

Not applicable

\section{Funding}

Support has been provided by Stellenbosch University Rural Medical Education Partnership Initiative (SURMEPI).

\section{Availability of data and materials}

The datasets used and/or analyzed during the current study are available from the corresponding author on reasonable request.

\section{Authors' contributions}

All authors contributed equally to this work. AO, KC, MC and CO collectively conceptualized the study and designed the data collection instrument. JPM and LN were instrumental in data collection and initial data analysis. SC performed further detailed analysis and interpretation of the data. JPM, KC, AO drafted the initial paper with initial contributions from CO. MC performed critical revision of the article and KC performed further edits. All co-authors approve of the version to be published.

\section{Ethics approval and consent to participate}

The study was approved by the scientific and ethical review committees of Stellenbosch University and Tygerberg Hospital, Cape Town, Western Cape, South Africa, and the Institutional Review Board at Children's Hospital Los Angeles. Informed consent to participate in the study was obtained from all participants.

\section{Consent for publication}

Not applicable

\section{Competing interests}

The authors declare that they have no competing interests.

\section{Author details}

${ }^{1}$ African Cancer Institute, Stellenbosch University, Cape Town, South Africa. 2Division of General Pediatrics, Department of Pediatrics, Children's Hospital Los Angeles, Los Angeles, CA, USA. ${ }^{3}$ Centre for Evidence Based Healthcare, Stellenbosch University, Cape Town, South Africa. ${ }^{4}$ Department of Respiratory Intensive Care, Groote Schuur Hospital, Cape Town, South Africa. ${ }^{5}$ Division of Hospital Medicine, Department of Pediatrics, Children's Hospital Los Angeles, 4650 Sunset Blvd, MS 94, Los Angeles, CA 90027, USA. ${ }^{6}$ Department of Pediatrics, Keck School of Medicine, University of Southern California, Los Angeles, CA, USA.

Received: 4 August 2017 Accepted: 14 December 2017

Published online: 12 January 2018

References

1. Centers for Disease Control and Prevention. Trends in length of stay for hospital deliveries - United States, 1970-1992. MMWR Morb Mortal Wkly Rep. 1995;44(17):335-7. 
2. Jones E, Taylor B, MacArthur C, Pritchett R, Cummins C. The effect of early postnatal discharge from hospital for women and infants: a systematic review protocol. Syst Rev. 2016;5:24.

3. Brown S, Small R, Argus B, Davis PG, Krastev A. Early postnatal discharge from hospital for healthy mothers and term infants. Cochrane Database Syst Rev. 2002:3:CD002958.

4. Farhat R, Rajab M. Length of postnatal hospital stay in healthy newborns and re-hospitalization following early discharge. N Am J Med Sci. 2011;3(3): 146-51.

5. Soskolne El, Shumacher R, Fyock C, Young ML, Schork A. The effect of early discharge and other factors on readmission rates of newborns. Arch Pediatr Adolesc Med. 1996;150(4):373-9.

6. Danielsen B, Castles AG, Damberg CL, Gould JB. Newborn discharge timing and readmission: California, 1992-1995. Pediatrics. 2000;106(1):31-9.

7. Liu LL, Clemens CJ, Shay DK, Davis RL, Novack AH. The safety of newborn early discharge: the Washington state experience. JAMA. 1997;278(4):293-8.

8. World Health Organization. WHO recommendations on postnatal care of the mother and newborn. Geneva: WHO; 2014.

9. Benitz WE. Committee on fetus and newborn, American Academy of Pediatrics. Hospital stay for healthy term newborn infants. Pediatrics. 2015;135(5):948-53.

10. Gupta P, Malhotra S, Singh DK, Dua T. Length of postnatal stay in healthy newborns and re-hospitalization following their early discharge. Indian J Pediatr. 2006:73(10):897-900.

11. Gupta P, Bisht HJ. Early discharge of normal term neonates: continued dilemma. Indian Pediatr. 2001;38(12):1374-81.

12. Hagan JFSJ, Duncan PM. Bright futures: guidelines for health supervision of infants children and adolescents. 3rd ed. American Academy of Pediatrics: Elk Grove Village; 2008.

13. Meara E, Kotagal UR, Atherton HD, Lieu TA. Impact of early newborn discharge legislation and early follow-up visits on infant outcomes in a state Medicaid population. Pediatrics. 2004;113(6):1619-27.

14. Shakib J, Buchi K, Smith E, Korgenski K, Young PC. Timing of initial well-child visit and readmissions of newborns. Pediatrics. 2015;135(3):469-74

15. Motara F, Ballot DE, Perovic O. Epidemiology of neonatal sepsis at Johannesburg hospital. South Afr J Epidemiol Inf. 2005;20(3):90-3.

16. The National Maternity Guidelines Committee. Guidelines for maternity care in South Africa. 4th ed. Republic of South Africa: National Department of Health; 2015.

17. Wadee H, Gilson L. Private wards in public hospitals: what are the policy and governance implications? A case study of Tygerberg academic hospital. Johannesburg: Centre for Health Policy, University of Witwatersand; 2007

18. Steyn PS, Odendaal HJ, Steyn DW. Trends in caesarean sections at Tygerberg hospital, South Africa: a 20-year experience. Cent Afr J Med. 1998; 44(9):219-23.

19. Madlon-Kay DJ, Asche SE. Factors that influence the receipt of well-baby care in the first 2 weeks of life. J Am Board Family Med. 2006;19(3):258-64

20. Profit J, Cambric-Hargrove AJ, Tittle KO, Pietz K, Stark AR. Delayed pediatric office follow-up of newborns after birth hospitalization. Pediatrics. 2009; 124(2):548-54

21. Bernstein $H_{\text {, Spino }}$, Finch $\mathrm{S}$, Stoltz $\mathrm{R}$, Stark A, Woo H, et al. Inadequate attention given to jaundice in healthy term infants during the first postpartum week. Pediatr Res. 2004:55(2):282A

22. Chen L, Qiong W, van Velthoven MH, Yanfeng Z, Shuyi Z, Ye L, et al. Coverage, quality of and barriers to postnatal care in rural Hebei, China: a mixed method study. BMC Pregnancy Childbirth. 2014;14:31.

23. Kanté AM, Chung CE, Larsen AM, Exavery A, Tani K, Phillips JF. Factors associated with compliance with the recommended frequency of postnatal care services in three rural districts of Tanzania. BMC Pregnancy Childbirth. 2015;15:341.

24. Somefun OD, Ibisomi L. Determinants of postnatal care non-utilization among women in Nigeria. BMC Res Notes. 2016;9:21.

25. Mohan D, Gupta S, LeFevre A, Bazant E, Killewo J, Baqui AH. Determinants of postnatal care use at health facilities in rural Tanzania: multilevel analysis of a household survey. BMC Pregnancy Childbirth. 2015;15:282.

26. Titaly CR, Dibley MJ, Roberts CL. Factors associated with non-utilisation of postnatal care services in Indonesia. J Epidemiol Community Health. 2009; 63(10):827-31

27. Karra M, Fink G, Canning D. Facility distance and child mortality: a multicountry study of health facility access, service utilization, and child health outcomes. Int J Epidemiol. 2017;46(3):817-26.
28. Titaley CR, Hunter CL, Heywood P, Dibley MJ. Why don't some women attend antenatal and postnatal care services?: a qualitative study of community members' perspectives in Garut, Sukabumi and Ciamis districts of west Java Province, Indonesia. BMC Pregnancy Childbirth. 2010;10:61.

29. Ugboaja JO, Berthrand NO, Igwegbe AO, OBI-Nwosu AL. Barriers to postnatal care and exclusive breastfeeding among urban women in southeastern Nigeria. Niger Med J. 2013;54(1):45-50.

30. Syed U, Khadka N, Khan A, Wall S. Care-seeking practices in South Asia: using formative research to design program interventions to save newborn lives. J Perinatol. 2008;28(Suppl 2):S9-13.

31. Dhaher E, Mikolajczyk RT, Maxwell AE, Krämer A. Factors associated with lack of postnatal care among Palestinian women: a cross-sectional study of three clinics in the West Bank. BMC Pregnancy Childbirth. 2008:8:26.

32. O'Donnell HC, Trachtman RA, Islam S, Racine AD. Factors associated with timing of first outpatient visit after newborn hospital discharge. Acad Pediatr. 2014;14(1):77-83

33. Feinberg AN, McAllister DG, Majumdar S. Does making newborn follow-up appointments from the hospital improve compliance? J Perinatol. 2004; 24(10):645-9.

34. Goyal NK, Hall ES, Kahn RS, Wexelblatt SL, Greenberg JM, Samaan ZM, et al. Care coordination associated with improved timing of newborn primary care visits. Matern Child Health J. 2016;20(9):1923-32

35. McConnell M, Ettenger A, Rothschild CW, Muigai F, Cohen J. Can a community health worker administered postnatal checklist increase health-seeking behaviors and knowledge?: evidence from a randomized trial with a private maternity facility in Kiambu County, Kenya. BMC Pregnancy Childbirth. 2016;16(1):136.

36. Hannan J, Brooten D, Page T, Galindo A, Torres M. Low-income first-time mothers: effects of APN follow-up using mobile technology on materna and infant outcomes. Glob Pediatr Health. 2016;3:2333794X16660234.

37. Ahlers-Schmidt CR, Chesser AK, Nguyen T, Brannon J, Hart TA, Williams KS, et al. Feasibility of a randomized controlled trial to evaluate text reminders for immunization compliance in kids (TRICKs). Vaccine. 2012;30(36):5305-9.

\section{Submit your next manuscript to BioMed Central and we will help you at every step:}

- We accept pre-submission inquiries

- Our selector tool helps you to find the most relevant journal

- We provide round the clock customer support

- Convenient online submission

- Thorough peer review

- Inclusion in PubMed and all major indexing services

- Maximum visibility for your research

Submit your manuscript at www.biomedcentral.com/submit 